\title{
A calculation code for the air pollution valuation produced by duty vehicles moving in an urban area
}

\author{
A. Nordio, E. Gattorna \& A. Baudà \\ Department of Machines, Energetic Systems and Transport, \\ Transportation Section, Genoa University, Italy
}

\begin{abstract}
Scientific research that started three years ago and was first developed in a Ph.D., has resulted in important results in producing a calculation code in "Excel" that values the main pollutant emissions $\left(\mathrm{CO}, \mathrm{NO}_{\mathrm{x}}, \mathrm{VOC}\right.$ and $\left.\mathrm{PM}\right)$ produced by duty vehicles moving in an urban area. Emissions were obtained by studying data about the main geometrical and flow features of the transport network in the area covered. Two mathematical models were integrated in the developed code, a flow and an emission model respectively. The flow simulation model determines, after a calibration according to the particular urban area in examination, the average vehicular speed on a single homogenous branch of a road network. So, when the average speed is fixed, it is possible to calculate the polluting emissions through the definition of an opportune emission model integrated in the code. The emission model is based on the CORINAIR methodology, implemented in the COPERTIII program (COmputer Programme to calculate Emissions from Road Transport) that, where necessary, has been modified according to experimental results, without distorting its basic philosophy. In conclusion, the calculation code allows for making choices in the transport field considering environmental sustainability aspects in the urban planning analysis, and it represents a good decision support system (DSS).

Keywords: air pollution, flow model, emission model, emission factor, urban road traffic, duty vehicle, COPERT program, corinair methodology, decision support system.
\end{abstract}




\section{Introduction}

The problem of air pollution in urban areas is particularly serious today. Polluting emissions like Carbon Monoxide (CO), the Volatile Organic Compounds (VOC), the Nitrogen Oxides $\left(\mathrm{NO}_{\mathrm{x}}\right)$ and the Particulate Matters (PM) are mainly generated by road transport. There are different categories of vehicles that contribute to the air pollution, from cars to trucks, from motorcycles to buses. In this work we concentrate our researches on the light and heavy duty vehicles, which are particularly polluting.

The methodology of study used in the Ph.D research (Nordio [1]) is based on these steps:

- the choice and the following elaboration of a flow model able to estimate the traffic average speeds on a whole road network in the Genoa urban area (Italy, Liguria Region) that, for the particular territorial orography, introduces different aspects in comparison to the other Italian urban realities;

- the choice and the following elaboration of an emission model able to estimate the duty vehicles emissions in Genoa;

- the Excel implementation of the built models with the aim to immediately value the pollutant emissions;

- the verification of the results through the calculation of the average speeds and the following emissions really produced by the running commercial vehicles on an urban path of Genoa with known flow and geometric features.

This paper doesn't study the dispersion model that is based on weather conditions (wind, pressure, air density, etc.); therefore, it doesn't calculate the pollutants concentrations. The reference scheme of the followed analysis is illustrated in fig. 1:

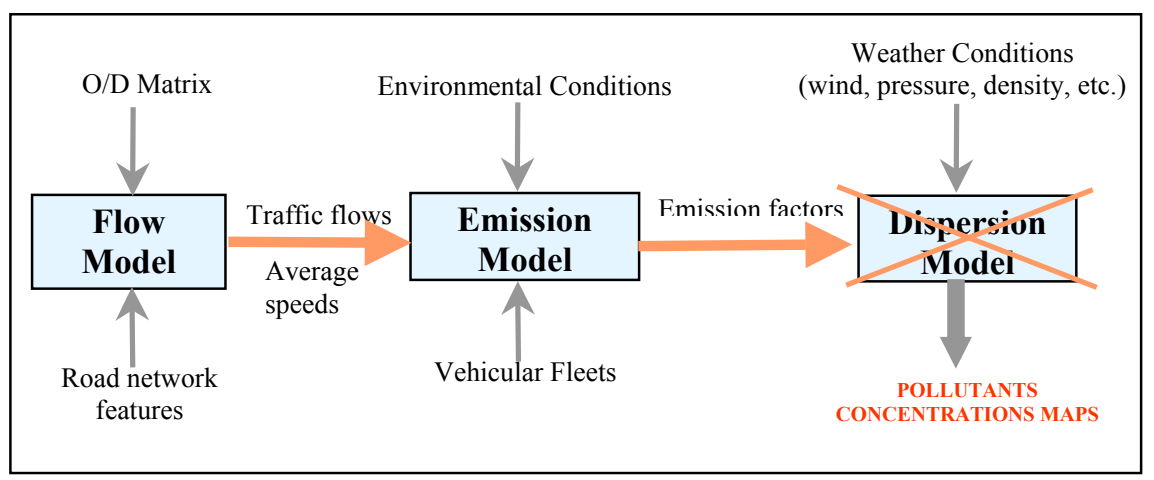

Figure 1: Reference scheme for the methodology of pollutant study.

\section{The flow model}

Two existing flow models have been compared: the Davidson (Taylor [2]) and the B.P.R. (Bureau of Public Roads) models. Considering its simple use, the small amounts of input data required in order to produce a working model, the 
flexibility of its use for all the roads having the same flow features and the greater predisposition to application on a whole road network, we chose the flow model proposed by the American B.P.R. This model supplies the average speed ' $\mathrm{v}_{\mathrm{m}}$ ' in $[\mathrm{km} / \mathrm{h}]$ of a running vehicular flow ' $\Phi$ ' $[\mathrm{veh} / \mathrm{h}]$, whose geometric features are not stringently necessary. It is undeniable the advantage of such a problem approach that excludes a detailed knowledge about, for example, road gradients, and lane breadths etc. that are not easily findable. The mathematical formulation follows:

$$
\frac{v_{m}}{v_{o}}=\frac{1}{1+\alpha \cdot\left(\frac{\Phi}{S}\right)^{\beta}}
$$

Therefore it is necessary to know the free flow speed ' $v_{\mathrm{o}}$ ', the saturation flow 'S' and two parameters, ' $\alpha$ ' and ' $\beta$ ', that are useful to calibrate the same model.

\subsection{Model calibrating}

To calibrate the flow model in operation with the Genoese urban reality we used the collected data in "MERCI" [3], a project financed by the Italian Ministry, and "MEROPE" [4], a European project (Interreg IIIB - Medocc area). In particularly, we have used the data related to 30 road arcs on the Genoa urban network (fig. 2), from "Fiumara" to "Caricamento", with known length, hourly flow, and average speed. These arcs are connected by 22 different nodes represented by road crossings.

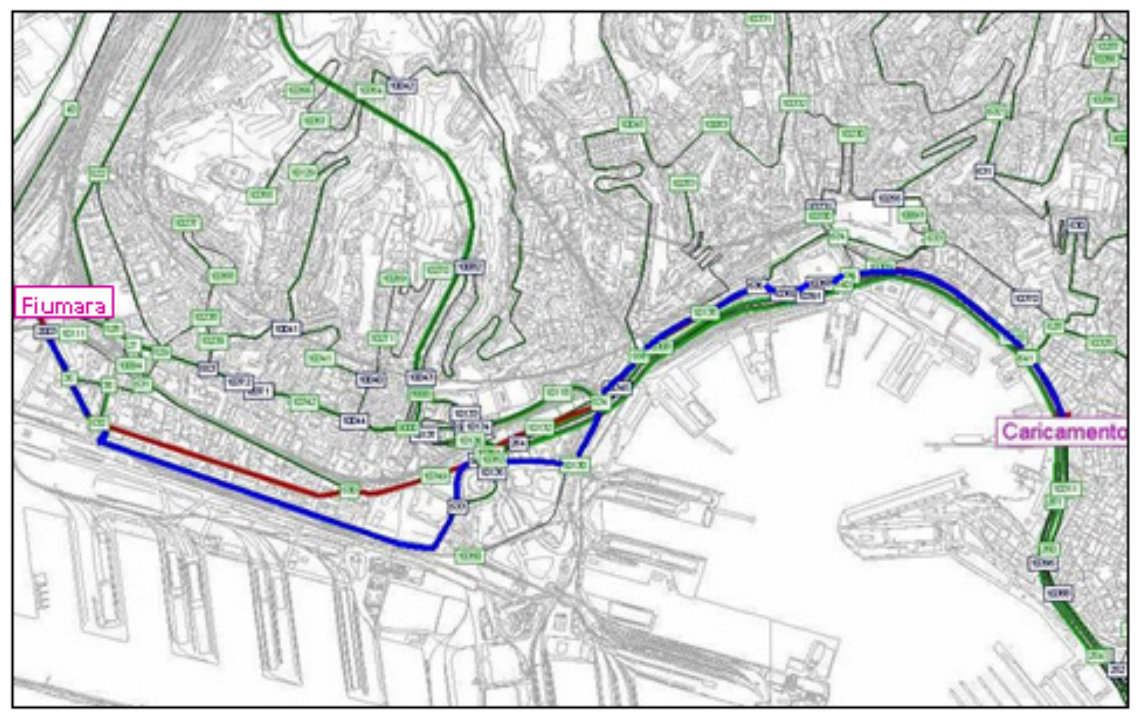

Figure 2: $\quad$ Studied road trip, Fiumara $\leftarrow \rightarrow$ Caricamento (Genoa, Italy). 
We fixed the free speed ' $v_{0}$ ' to the conventional value of $50 \mathrm{~km} / \mathrm{h}$ to generalize the problem for future applications. In other words, we hypothesized that the hauler doesn't ever reach the speed limit in urban area. For the saturation flow ' $\mathrm{S}$ ', we applied the Highway Capacity Manual formulation:

$$
S=c \times S_{o} \times \eta_{l}
$$

where ' $c$ ' is the number of lanes per direction, ' $S_{o}$ ' is the ideal saturation flow per lane (fixed in $1.800 \mathrm{veh} / \mathrm{h}$ ), ' $\eta_{l}$ ' is a coefficient for the breadth of lanes (fixed in 0.97). The calibration has been verified with the application of a correlation factor $\left(\mathrm{R}^{2}=1 \rightarrow\right.$ perfect correlation; $\mathrm{R}^{2}=0 \rightarrow$ no correlation) between the calculated and measured speed in "MEROPE" projects. Then, when the calibration was carried out, we have established the following $\alpha \& \beta$ parameters (fig. 3, 4): $\alpha=4,1 \& \beta=2,1$ if the road arc has a flow $\leq 2000 \mathrm{veh} / \mathrm{h} ; \alpha=5,1 \&$ $\beta=1,4$ if the road arc has a flow $>2000 \mathrm{veh} / \mathrm{h}$.

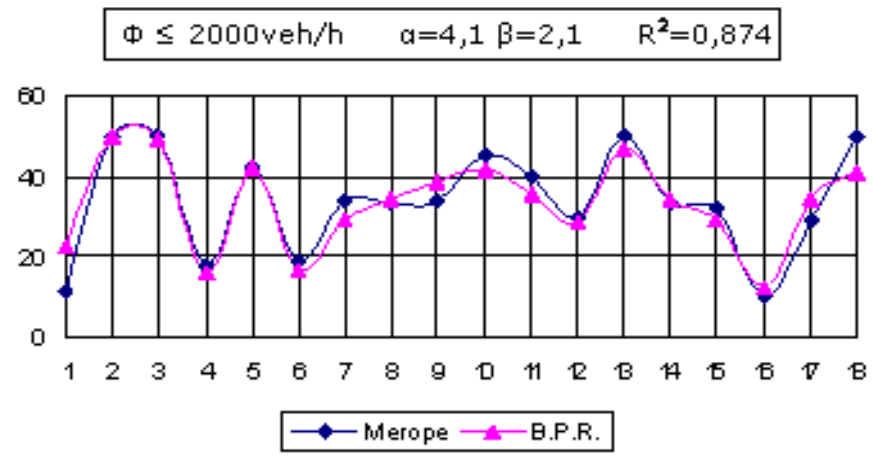

Figure 3: $\quad \alpha \& \beta$ parameters if $\phi \leq 2000 \mathrm{veh} / \mathrm{h}$.

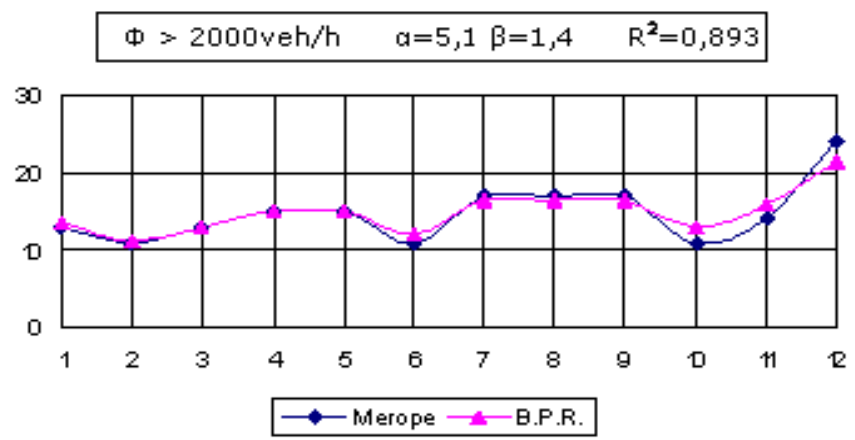

Figure 4: $\quad \alpha \& \beta$ parameters if $\phi>2000 \mathrm{veh} / \mathrm{h}$. 


\section{The emission model}

The methodology selected for the emission calculation is the CORINAIR [5] methodology, implemented in the COPERTIII program (COmputer Programme to calculate Emissions from Road Transport) Eggleston et al [6]. The European methodology has been re-elaborated and changed to be applied to the Genoa urban area. Therefore, the initial wide method built for an annual national inventory has been transformed, reducing its spatial dimension to the urban network and its temporal dimension to the hourly one (base emission factor). We specify that the used emission model considers some features like the road gradient, the load factor, the vehicles age (mileage), the improved fuels and enhanced inspection and maintenance scheme, whose calculation procedures are noted in literature, have been preventively verified, modified and calibrated for the correct application in the Genoa urban area. So, we have obtained a new emission factor more respondent to a real pollution phenomenon (corrected emission factor), that concerns only duty vehicles and does not consider the contribution of other kinds of vehicles normally moving in an urban area.

In COPERT, total emissions $\left(\mathrm{E}_{\text {TOTAL }}\right)$ are calculated in [g] by summing three different emission sources:

$$
E_{\text {TOTAL }}=E_{H O T}+E_{C O L D}+E_{E V A P}
$$

By hot emission $\left(\mathrm{E}_{\text {hot }}\right.$ ) we mean by convention the emissions occurring under a thermally stabilised engine and exhaust after treatment conditions; the cold emissions $\left(\mathrm{E}_{\text {cold }}\right)$ are calculated as an extra emission over the hot emissions, during the warming-up phase (cold start); the evaporative emissions $\left(\mathrm{E}_{\text {evap }}\right.$ ) depend from the fuel evaporation.

Vehicle emissions are heavily dependent on the engine operation conditions. Different driving situations impose different engine operation conditions and therefore a distinct emission performance. In this work we consider the total emissions average speed dependent, because the aim of the research is to calculate the average emission of a vehicle fleet on a particular road path, without concentrating the attention on a single vehicle. This is the possible approach for an urban planning analysis.

Now, in general, each emission source (per period of time) is calculated in [g] as an emission factor $[\mathrm{g} / \mathrm{km}]$ for a certain pollutant and vehicle class $\times$ number of vehicles [veh] per vehicle class $\times$ mileage per vehicle $[\mathrm{km} / \mathrm{veh}]$ per vehicle class. In the following paragraph the baseline emission factors are formulated.

\subsection{Baseline emission factor}

The baseline emission factors (factors in standard conditions) are defined in $[\mathrm{g} / \mathrm{km}]$ by experimental equations in the second degree where the emissions are calculated in function of the average speed $(v)$ of the running vehicular flow per $\gamma_{\mathrm{i}}$, vehicle class dependent coefficients: 


$$
e=\gamma_{1} \cdot v^{2}+\gamma_{2} \cdot v+\gamma_{3}
$$

Now hot and cold emissions have been calculated using the original formulations without changes. Instead, for evaporative emissions we have changed the CORINAIR methodology. We took back and modified the CONCAWE [7] methodology (CONservation Clean Air and Water in Europe, 1992) that considers the evaporative emissions by adding hot soak emissions and running losses neglecting the diurnal emissions (considered in CORIAIR). The hot soak emissions are the emissions caused when a hot engine is turned off. Heat from the engine and exhaust system increases the temperature of the fuel in the system that is no longer flowing. So, in this work hot soak emissions appears negligible because it's necessary over a longer time to start the emissions losses phenomenon. In fact, we suppose that vehicles are moving on a certain road with short stops to load and unload the goods. In conclusion, the final formulation to calculate evaporative emissions (naturally only for VOC) follows:

$$
E_{E V A P ; V O C}=N \cdot M \cdot \frac{R L}{45}
$$

where ' $\mathrm{N}$ ' is the number of vehicles [veh] in circulation on the urban network, ' $M$ ' is the total mileage per vehicle [ $\mathrm{km} / \mathrm{veh}]$, and ' $\mathrm{RL} / 45$ ' is the emission factor. In particular, 'RL' are the running losses [g] and ' 45 ' is the distance the vehicle has been driven during the test in $[\mathrm{km}]$. 'RL' formulation changes if we have controlled or uncontrolled vehicles.

Table 1: $\quad$ Running losses for evaporative emissions factors.

\begin{tabular}{|c|c|c|}
\hline \multirow{2}{*}{$\mathrm{RL}$} & Uncontrolled vehicle & $\begin{array}{c}\text { Controlled vehicle } \\
(\text { small carbon canister })\end{array}$ \\
\cline { 2 - 3 } & $\begin{array}{c}\text { Exp }(-5.967+0.04259 \\
\left.\mathrm{RVP}+0.1773 \mathrm{t}_{\mathrm{a}}\right)\end{array}$ & $0.1 *$ Uncontrolled \\
& & \\
\hline
\end{tabular}

In table 1 'RVP' is the fuel volatility in $[\mathrm{kPa}]$ and ' $\mathrm{t}$ ' ' is the average monthly ambient temperature in $\left[{ }^{\circ} \mathrm{C}\right]$.

\subsection{Emission corrections}

The baseline emission factors have to be corrected according to various effects: vehicle age (mileage), enhanced inspection and maintenance scheme (I\&M schemes), improved fuels, road gradient on heavy duty vehicles emissions, heavy duty vehicle load. In this work we used COPERT formulations without changes, except for the road gradient that is so different for each urban road of Genoa.

The road gradient effect has been calculated considering the MEET [8] methodology (Methodologies to Estimate Emissions from Transport, 1999), that uses six road gradient classes $( \pm 2 \%, \pm 4 \%, \pm 6 \%)$ instead of the only four COPERT classes. So the MEET methodology supplies a greater level of detail for road gradients from $0 \%$ to $\pm 4 \%$. 


\section{The calculation code}

The methodology described in the above paragraphs has been implemented in a calculation code that includes 30 Excel sheets. Each sheet represents a generic arc of the road network with homogenous flow features and contains the calculation methodology; so it is possible to estimate emissions of duty vehicles really circulating on the Genoa road network. Each calculation sheet is connected to another sheet, called the "User Interface", where the user can introduce all input data (geometric, flow and vehicles features) and can obtain output emissions. In table 2 the input and output data are collected.

Table 2: $\quad$ Input and output dataset.

\begin{tabular}{|c|c|c|c|}
\hline Input & Description & Output & Description \\
\hline $\mathrm{L}$ & Arc length [m] & $\mathrm{E}_{\mathrm{HOT}, \mathrm{i}}$ & $\begin{array}{l}\text { Total Hot Emission }[\mathrm{g}] \\
\text { 'i' }=1 \div 4 \text { pollutant type }\end{array}$ \\
\hline $\mathrm{P}$ & Road gradient [\%] & $\mathrm{E}_{\mathrm{COLD}, \mathrm{i}}$ & $\begin{array}{l}\text { Total Cold Emission [g] } \\
\text { ' } \mathrm{i} \text { ' }=1 \div 4 \text { pollutant type }\end{array}$ \\
\hline$\phi$ & Vehicular flow [veh/h] & $\mathrm{E}_{\text {EVAP,VOC }}$ & $\begin{array}{l}\text { Total evaporative } \\
\text { emission }[\mathrm{g}]\end{array}$ \\
\hline c & Lanes number & $\mathrm{E}_{\mathrm{TOT}, \mathrm{i}}$ & $\begin{array}{l}\text { Total Emission }[\mathrm{g}] \\
\text { ' } \mathrm{i} \text { ' }=1 \div 4 \text { pollutant type }\end{array}$ \\
\hline$\overline{t_{a}}$ & $\begin{array}{l}\text { Ambient temperature } \\
{\left[{ }^{\circ} \mathrm{C}\right]}\end{array}$ & $\mathrm{E}_{\mathrm{HOT}, \mathrm{i}}(\mathrm{I} \& \mathrm{M})$ & $\begin{array}{l}\mathrm{E}_{\mathrm{HOT}} \text { if an enhanced } \\
\mathrm{I} \& \mathrm{M} \text { scheme is in place } \\
\text { ' } \mathrm{i} \text { ' = } 1 \div 4 \text { pollutant type }\end{array}$ \\
\hline $\mathrm{h}$ & Valuation Time [h] & $\mathrm{E}_{\mathrm{TOT}, \mathrm{i}}(\mathrm{I} \& \mathrm{M})$ & $\begin{array}{l}\mathrm{E}_{\text {TOT }} \text { if an enhanced } \\
\mathrm{I} \& \mathrm{M} \text { scheme is in place } \\
\text { ' } \mathrm{i} \text { ' = } 1 \div 4 \text { pollutant type }\end{array}$ \\
\hline $\mathrm{V}_{\mathrm{mm}}$ & $\begin{array}{l}\text { Measured mean speed } \\
{[\mathrm{km} / \mathrm{h}]}\end{array}$ & & \\
\hline $\mathrm{N}_{\mathrm{i}}$ & $\begin{array}{l}\text { Number of duty } \\
\text { vehicles per 'i' } \\
\text { vehicular category }\end{array}$ & & \\
\hline $\mathrm{N}_{\mathrm{i}, \mathrm{ce}}$ & $\begin{array}{l}\text { Number of light duty } \\
\text { vehicles with cold start } \\
\text { engine per ' } i \text { ' vehicular } \\
\text { category }\end{array}$ & & \\
\hline $\mathrm{M}_{\mathrm{MEAN}, \mathrm{i}}$ & $\begin{array}{l}\text { Mean fleet mileage } \\
{[\mathrm{km}] \text { per 'i' vehicular }} \\
\text { category }\end{array}$ & & \\
\hline $\mathrm{LP}_{\mathrm{i}}$ & $\begin{array}{l}\text { Load factor [\%] per 'i' } \\
\text { vehicular category }\end{array}$ & & \\
\hline
\end{tabular}

We specify that if the measured mean speed $\left(\mathrm{V}_{\mathrm{mm}}\right)$ isn't available the code automatically calculates the average speed using the flow model (calculated mean speed, $\mathrm{V}_{\mathrm{mc}}$ ). Therefore, in reality, the necessary input data for developing 
the flow model are: the vehicular flow ' $\phi$ ' and the lane number ' $c$ ' for each arc. At the same way, the emission model can operate with only these variables: the arc length ' $\mathrm{L}$ ', the measured mean speed ' $\mathrm{V}_{\mathrm{mm}}$ ' and the number of duty vehicles $\mathrm{N}_{\mathrm{i}}$ for each arc. The input data as the ambient temperature ' $\mathrm{t}_{\mathrm{a}}$ ' and the number of light duty vehicles with cold start engine ' $\mathrm{N}_{\mathrm{i}, \mathrm{ce}}$ ' are useful to calculate the overemission due to cold engine. The rest of the input data as the mean fleet mileage ' $\mathrm{M}_{\mathrm{MEAN}, \mathrm{i}}$ ', the load factor for the heavy duty vehicle ' $\mathrm{LP}_{\mathrm{i}}$ ' and the road gradient ' $\mathrm{P}$ ' are used to make important corrections in the models. However, the data not essential to calculate the basis hot emissions can be considered facultative. In fact, for the methodology functioning, at least for the basis level, it is only necessary for the calculation of the hot emissions. The cold-start emissions are considered over-emissions of the hot one and are important just for low temperature; the evaporative emissions, even if directly linked to the ambient temperature value, have in this analysis low importance because of their low level, so they could be neglected.

The output data are collected within the User Interface in a resume table divided in four parts, depending on the pollutant $\left(\mathrm{CO}, \mathrm{NO}_{\mathrm{x}}, \mathrm{VOC}\right.$ and $\left.\mathrm{PM}\right)$. Every part includes five columns, each one for the emission type: $\mathrm{E}_{\mathrm{HOT}}, \mathrm{E}_{\mathrm{COLD}}$, $\mathrm{E}_{\mathrm{TOT}}, \mathrm{E}_{\mathrm{HOT}}(\mathrm{I} \& \mathrm{M}), \mathrm{E}_{\mathrm{TOT}}(\mathrm{I} \& \mathrm{M})$. About VOC the output parameters are six: one for evaporative emissions ( $\left.\mathrm{E}_{\mathrm{EVAP}, \mathrm{VOC}}\right)$. Moreover, six different histograms linked to the results are available.

The first histogram (fig. 5) provides total emissions [g] per pollutant for each examined arc. In particular, all figures below show the results of the analysis for the Genoa urban road network.

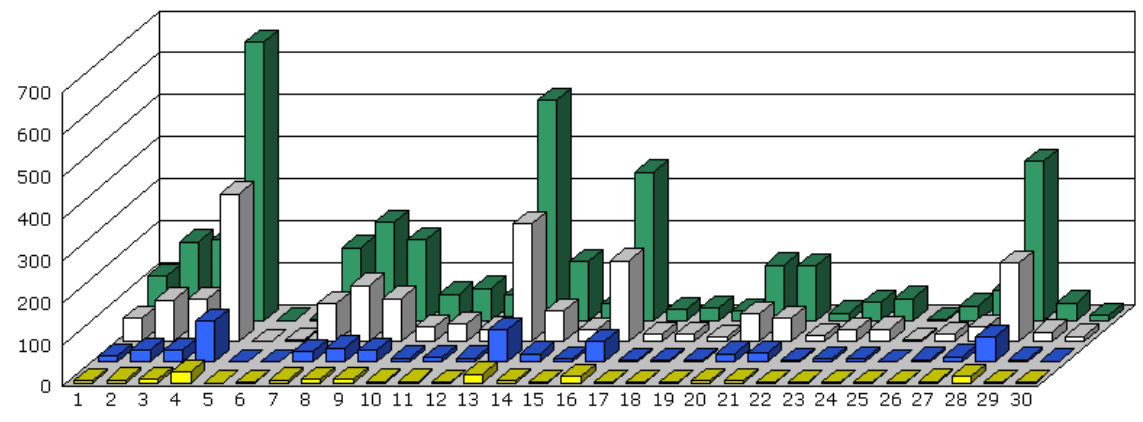

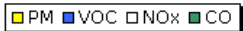

Figure 5: User interface - total emissions [g] per pollutant for each arc.

The second and third histograms provide total emissions [g] per pollutant (NOx - CO and VOC - PM) and emission type (hot and cold) for each examined arc. For example, see figure 6 about NOx and CO.

The fourth and fifth histograms provide respectively the total emissions [g] per pollutant and per emission type (hot, cold, evaporative) for the whole urban network. For example, see figure 7 per emission type. 


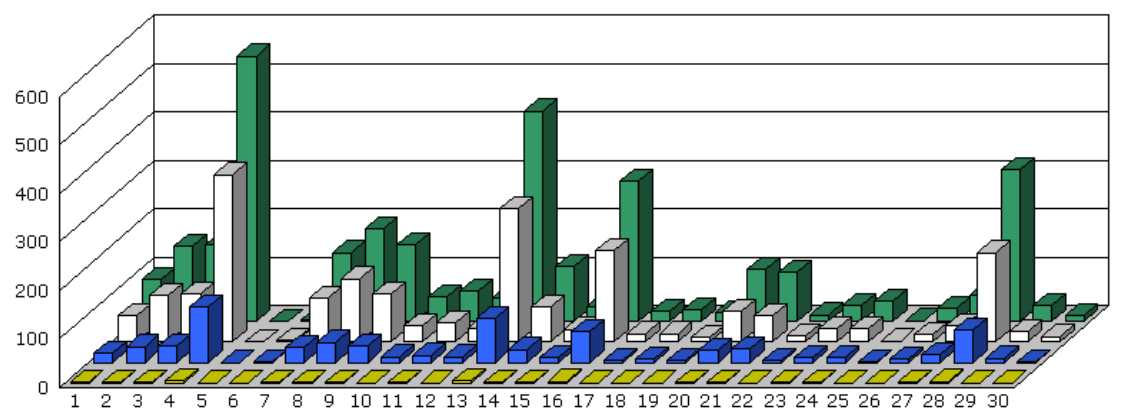

$\square \mathrm{NOX}(\mathrm{C}) \square \mathrm{CO}(\mathrm{C}) \square \mathrm{NOX}(\mathrm{H}) \square \mathrm{CO}(\mathrm{H})$

Figure 6: User interface - (C)old and (H)ot emissions [g] per NOx \& CO for each arc.

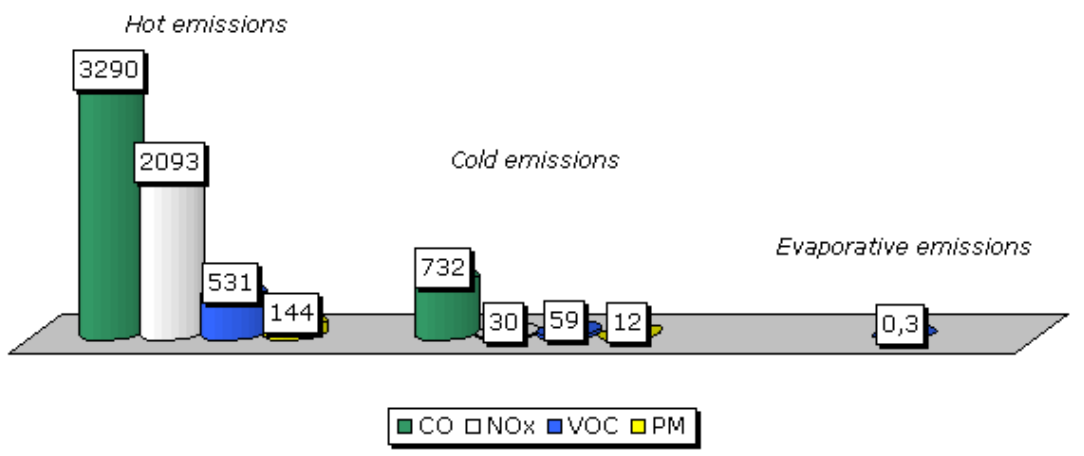

Figure 7: User interface - total emissions [g] per emission type about the whole urban network.

The sixth histogram provides the total emissions [g] per pollutant and per emission type (hot, cold, evaporative) for the whole urban network comparing the situation with an enhanced I\&M scheme.

\section{Conclusion}

We specify that the comparison among emissions measured within "Merope" project and emissions calculated with the present methodology on the whole urban network shows a variation between 4,7\% and 5,7\%. These variations and other statistic analysis show that the methodology can have a good application on the Genoa territory and as it has a greater propensity to an application on the whole road network rather than on the single arc. 
In conclusion, this Ph.D. research allows the taking of decisions about transport urban planning considering several aspects linked to the environmental sustainability. For example, inside an urban network it's very important to know which is the preferential path for the commercial vehicles with the aim to generate the lowest environmental impact. Moreover, in the city logistics field it's interesting to have the right tools, like the model created, to understand the best urban distribution of goods in order to achieve the reduction of costs linked to the air quality or to the trip time.

Fort the air quality study this code can estimate the part of the air pollution deriving from a present or a foreseen duty vehicle traffic. Therefore, it represents a good decision support system (DSS) in the Genoa territory. However its application is not excluded in different urban realities.

\section{References}

[1] Nordio, A., The study of the air pollution produced by duty vehicles in an urban area as an analysis tool to understand the economic-environmental value of a transport planning. An intermodal technical solution for a 'sustainable' urban mobility. The Genoa case study., Ph.D Research in Fluid Machines, University of Genoa, Faculty of Engineering, Genoa, Italy, 2007.

[2] Taylor, M.A.P., On Davidson's flow rate travel time relationship, Australian Road Research, 1977.

[3] Municipality of Genoa, M.E.R.Ci Project, Final Report, 2003.

[4] Municipality of Genoa, Merope Project, INTERREG III B - MEDOCC Programme, Final Report, 2004.

[5] Commission of the European Communities, CORINAIR - European inventory of emissions of pollutants in the atmosphere, Corinair Project, 1997 (\& updating versions).

[6] Eggleston, S., Gorissen, N., Hassel, D., Hickman, A.J., Joumard, R., Ntziachristos, L., Rijkeboer, R., Samaras, Z., White, L. \& Zierock, K.H., COPERTIII Methodology and Emission Factors, Version 2.1, Technical Report No. 49, ETC/AEM, European Environment Agency, 1997 (\& updating versions).

[7] CONCAWE (1990a), The effects of temperature and fuel volatility on vehicle evaporative emissions, Report $N^{\circ}$ 90/51, 1990.

[8] LAT/AUTh, INRETS, University of Limerick, Methodologies for Estimating Air Pollutant Emissions From Transport - MEET, Deliverable $N^{\circ}$ 9: Gradient influence, TÜV Rheinland, Cologne, Germany, 1997. 